\title{
O monge, o executivo e o estudante ludibriado: uma análise empírica sobre leitura eficaz entre alunos de administração*
}

\author{
Monks, Managers and Mislead Students: An empirical analysis of effective reading \\ among Business undergrads
}

\author{
José Luis Felicio Carvalho ${ }^{1}$ \\ Frederico Antonio A. Carvalho ${ }^{2}$ \\ Carol Bezerra ${ }^{3}$
}

\begin{abstract}
Resumo
Os cursos de graduação em administração reúnem o maior contingente de estudantes universitários em todo o sistema superior de ensino no Brasil. Por outro lado, desde o surgimento das primeiras escolas, o processo de formação dos futuros gestores e gerentes brasileiros vem sendo alvo de críticas contundentes, mesmo por parte de acadêmicos da área. Essas críticas se referem não somente à mercantilização do ensino superior em administração, como também às consequências, para praticantes e estudantes, da emergência do fenômeno pop em gestão. A desordem perscrutada nesta pesquisa relaciona-se à dificuldade apresentada por alunos de administração quanto à distinção entre livros populares de gestão, livros esotéricos e livros de autoajuda, bem como ao debate sobre as consequências advindas de uma incapacidade de se estabelecer uma clara distinção entre esses três gêneros literários. Ao analisar os resultados de uma pesquisa de campo conduzida em uma universidade pública situada na cidade do Rio de Janeiro - cujos dados foram coletados por meio de questionários e submetidos a tratamento estatístico não-paramétrico -, foi possível destacar as relações entre os três tipos de literatura, no que se refere à percepção dos alunos. Os resultados, que servem como alerta para aqueles que se preocupam com o ensino e com a disseminação do conhecimento em administração no Brasil, indicam que os futuros administradores não parecem distinguir se estão lendo livros de autoajuda, esotéricos ou de popmanagement.
\end{abstract}

Palavras-chave: leitura na graduação; ensino de administração; literatura pop-management; estatística não-paramétrica.

\begin{abstract}
In Brazil, enrollment in Business programs is higher than in any other university program. At the same time, ever since the first schools appeared, prospective managers' education has received sharp criticism even from academics. These criticisms refer both to the allegedly excessive commercialization of educational praxis, and to likely impacts - on students and on practitioners - from so-called pop management culture that appears to have been emerging for some time now. The particular issue to be investigated here is related to how difficult it might be for Business undergraduates to distinguish between excerpts of books on esoteric themes, self-help or texts popularizing managerial subjects. The consequences of these difficulties are also discussed. Data have been collected from a survey applied to a convenience sample of undergraduate students in a public university in Rio de Janeiro, Brazil. Both the nature and size of the sample indicate that nonparametric statistics should be preferred when analyzing empirical figures. Findings have shown that respondents have mostly not been able to distinguish between the three genres in the short texts they have read. These results should serve as an additional warning to anyone involved in Business education in Brazil.
\end{abstract}

Key words: reading skills among undergraduate students; business education; pop-management literature; nonparametric statistics.

\footnotetext{
Artigo submetido em setembro de 2009 e aceito para publicação em fevereiro de 2010.

* Uma versão preliminar deste estudo foi apresentada no XXXI Encontro da Associação Nacional de Pós- Graduação e Pesquisa em Administração, realizado no Rio de Janeiro em 2007.

1 Doutor em Administração pela Pontifícia Universidade Católica do Rio de Janeiro/ PUC-Rio. Professor Adjunto III - Faculdade de Administração e Ciências Contábeis da Universidade Federal do Rio de Janeiro (FACC/UFRJ). Endereço: Av. Pasteur, 250 / sala 239, Praia Vermelha - Rio de Janeiro/RJ - Brasil - CEP: 22290-902. E-mail : zkcarvalho@hotmail.com

${ }^{2}$ Doutor em Ciências Econômicas pela Université Catholique de Louvain. Professor Adjunto IV da Faculdade de Administração e Ciências Contábeis da Universidade Federal do Rio de Janeiro (FACC/UFRJ). Endereço: Av. Pasteur, 250 / sala 239 - Praia Vermelha - Rio de Janeiro/RJ - Brasil - CEP: 22290-902. E-mail: fdecarv@gmail.com.

${ }^{3}$ Bacharel em Administração - Faculdade de Administração e Ciências Contábeis da Universidade Federal do Rio de Janeiro (FACC/UFRJ). Endereço: Av. Pasteur, 250 / sala 239 - Praia Vermelha - Rio de Janeiro/RJ - Brasil - CEP: 22290-902. E-mail: carol.bezerra@oi.com.br
} 


\section{Introdução}

Nas últimas décadas, multiplicaram-se as escolas de formação de administradores, fazendo com que a graduação em administração seja, atualmente, a modalidade com o maior número de matrículas entre as instituições de ensino superior no Brasil, representando 12,8\% dos universitários brasileiros em 2006 (TAKAHASHI, 2008). A expansão do ensino superior em administração ocorreu numa velocidade espantosa: de dois cursos em 1954, passou-se a 2.484 cursos de graduação em 2005, com a imensa maioria desse contingente em escolas privadas (PARDINI; FALCÃO; SANTOS, 2008).

Desde a criação dos primeiros cursos de administração, entretanto, alguns actantes envolvidos na formação dos futuros gerentes e gestores vêm se mostrando insatisfeitos com o resultado alcançado pelos cursos de graduação, questionando tanto a eficácia do processo educativo (SILVA; FISCHER, 2008), quanto a responsabilidade do alunado com respeito aos problemas correspondentes. Por exemplo, Mello Jr e Mello (2008, p.7) asseveram que alunos de administração "não gostam de ler e [que] a maioria não gosta porque não sabe mesmo", defendendo que predomina nos cursos "a arte da embromação".

Ainda que não se creia na possibilidade de diagnosticar de modo tão simplista uma questão assim complexa, por outro lado, talvez, seja profícuo reconhecer que os problemas com a leitura desempenham um papel determinante para a permanência desse quadro desalentador - especialmente, no que tange a um tipo específico de leitura, própria do universo da administração. Pesquisas correlacionando dificuldades no processo educacional e problemas de compreensão em leitura foram registrados em diversos campos de formação universitária, apontando "deficiências de compreensão e o escasso hábito de leitura entre universitários como responsáveis, em grande parte, pelo baixo desempenho acadêmico desses alunos" (SAMPAIO; SANTOS, 2002, p.32). Na formação dos administradores, tais problemas são agravados por peculiaridades do universo habitado por gerentes, gestores e seus aprendizes.

Este artigo tem como preocupação central entender se e como o desenvolvimento da indústria cultural de popmanagement (cf WOOD Jr.; DE PAULA, 2001), em anos recentes, pode ter provocado a contaminação de escolas de graduação em administração no Brasil por um tipo de literatura descartável que antes ficava restrito aos agora decadentes cursos de MBA (MINTZBERG, 2006) ou às seções reservadas à mídia de negócios nas redes populares de livrarias e, mesmo, em bancas de jornal. Cada vez mais dinheiro é investido para promover essa duvidosa linha editorial, responsável por explosões de vendagens a cada lançamento. Uma das motivações para a pesquisa nasce, precisamente, da constatação de que as estantes de livrarias repletas de livros de negócios estão cada vez mais semelhantes - no que tange a título, diagramação, cores das capas e, obviamente, ao conteúdo - às estantes com livros esotéricos e de autoajuda. Não é raro encontrar essas três categorias misturadas em uma mesma seção.

Três consequências imediatas dessa situação, no mínimo, surpreendente são:

1. o enriquecimento inaudito dos barões da "indústria do management" (cf. WOOD Jr.; DE PAULA, op. cit.), estejam eles à frente de uma grande editora, em uma empresa de consultoria ou à frente de uma turma de estudantes;

2. a proliferação de um mercado de ideias cada vez menos reflexivo e menos democrático, baseado em princípios equivocados e subordinado a interesses de elites estrangeiras ou de elites locais comprometidas com tais interesses (cf. FARIA, 2006); e

3. retornando à proposição contemplada neste artigo, a colonização das mentes de jovens estudantes de administração desde seus primeiros contatos com a teoria, o que pode criar desvios de aprendizagem que acabarão por gerar deformidades em sua formação profissional e pessoal.

Mantendo o foco nessa questão, os pesquisadores percorreram salas de aula povoadas por alunos de administração em uma das maiores universidades federais do país - representando uma escola que obteve por repetidas vezes uma posição de destaque nas avaliações do extinto Exame Nacional de Cursos do Ministério da Educação -, para averiguar seu discernimento acerca da literatura em negócios, com relação à literatura 
esotérica e de autoajuda. A ideia da pesquisa estava relacionada a três pontos principais: (a) detectar a familiaridade dos estudantes com a literatura pop; (b) descobrir se os alunos seriam bem sucedidos em notar diferenças entre conteúdos pop, esotéricos e de autoajuda; e (c) mostrar a dimensão da eventual confusão para os alunos entre esses três gêneros.

Em princípio, pode-se perceber que os protagonistas dos livros de autoajuda e esotéricos também frequentam as páginas da literatura pop-management, muitas vezes, travestidos de gerentes milagrosos: guerreiros da luz, magos, bruxas, budas e anjos infestam as três formas literárias. A inquietação que motivou este estudo não abarca exatamente essa inacreditável transposição de fronteiras entre os gêneros, mas o fato de que esse movimento poderia passar despercebido por alguns dos melhores estudantes do país. A confirmação dessa suposição, no parecer dos autores deste artigo, traz duas implicações inter-relacionadas:

1. a percepção de que a literatura pop pode ser mais perniciosa para estudiosos e praticantes de administração do que se gostaria de acreditar; e

2. o entendimento de que também por esse mecanismo - há outros que provocam efeito semelhante os futuros administradores estão sendo espoliados com relação ao maior legado que se pode transmitir a eles, qual seja, a capacidade de empreender uma visão reflexiva e crítica diante da realidade.

Assim, o problema de pesquisa que se pretende analisar pode ser apresentado sob a forma da seguinte pergunta: do ponto de vista dos leitores, existem diferenças perceptuais significativas entre a literatura pop-management, os livros de autoajuda e os livros esotéricos? Essa pergunta é retomada e desagregada na terceira seção do artigo.

O estudo é constituído por esta introdução e quatro seções. Tomando por base o quadro teórico desenvolvido por Wood Jr. e de Paula (2001; 2002a; 2002b; 2003; 2006), a revisão bibliográfica contempla, na primeira seção, uma perspectiva crítica acerca da literatura de pop-management. Em seguida, delineiam-se os procedimentos metodológicos cumpridos durante a etapa empírica do trabalho. Na terceira seção são apresentados os resultados da pesquisa, que evidenciam a impossibilidade, para a amostra selecionada, de diferenciar literatura pop-management, esotérica e de autoajuda. A quarta seção apresenta as considerações finais.

\section{Quadro teórico referencial}

Esta seção expõe os fundamentos teóricos da pesquisa e compõe-se de quatro subseções. A primeira lança a noção de pop management, situando a "cultura do management" no âmbito organizacional. A manifestação do pop na literatura de gestão é tratada a seguir. A terceira subseção descreve como os autores e as obras pop acabam por integrar-se ao mundo literário a partir do mercado de trabalho para gerentes. Finalmente, a última subseção mostra a migração da literatura pop para a academia, acompanhada de outras formas ou gêneros não menos estranhos aos cânones educacionais.

\section{O alvorecer do "pop-management"}

Em um cenário socioeconômico caracterizado pelo efêmero, pelo descartável, pela espetacularização, pela complexidade e pelo hiperconsumo (DEBORD, 1998; LIPOVETSKI, 2004), o medo e a insegurança criam a permanente impressão de que todo conhecimento está fadado à obsolescência, o que se torna ainda mais patente na área da administração, dominada por discursos que celebram uma arena de negócios globalizada. A incessante procura por profissionais mais competentes gera demanda por administradores identificados com as características do sistema produtor, fortalecendo o crescimento da indústria do management (MICKLETHWAIT; WOOLDRIDGE, 1998; WOOD Jr., 2001), com suas promessas de soluções milagrosas, rápidas e fáceis, tanto no âmbito profissional quanto na vida pessoal.

A partir das ameaças de enxugamentos, de demissões e de terceirizações, os profissionais seguem os desígnios de um mercado de trabalho exigente e mutável. Passam, então, a garimpar revistas e livros, palestras-relâmpago 
e especializações que, acrescidos ao currículo, possam dar a impressão de que se "agregou valor" a sua "empregabilidade" ou que se investiu em "sinergia" e "não-conformidade", de modo a "otimizar" resultados usando jargões exaustivamente repetidos na literatura pop e reconhecidos como ridículos pelos próprios autores pop (ver FUGERE; HARDAWAY; WARSHAWSKY, 2007). Desse modo, o conhecimento é tratado como bem de aquisição: basta usar conforme as instruções (MATTOS, 2000).

Quando se vive em "um mundo obcecado pelo novo, habilitado por novidades artificiais, por eventos não espontâneos, em que a imagem parece mais fidedigna que o original" (MENDES, 2004, p.14), a realidade é posta de lado e o "fingir saber" vale mais do que o "saber fazer". Nesse mundo, a "realidade transforma-se naquilo sobre o qual é possível gerar uma reprodução equivalente, não o que pode ser reproduzido, mas o que é sempre reproduzido" (WOOD Jr., 2001, p.94); o pop-management responde a essas demandas.

No âmbito organizacional, a competitividade e a busca por sobrevivência surgem como legitimadores das ações da organização (NEPOMUCENO; MOREIRA, 2004, p.7). A ansiedade dentro das empresas gera uma falsa ideia de que a inovação é uma maneira de solucionar problemas, dando lugar aos modismos e ao charlatanismo: "Organizações que adotam inovações são percebidas como flexíveis e adaptáveis. Já aquelas que não adotam inovações são vistas como inertes ou patológicas" (WOOD Jr., 2001, p.158). Nesse contexto caracteriza-se a cultura do management, definida por Wood Jr e de Paula (2002a, p.3-4) como um conjunto de pressupostos compartilhados nas empresas e no meio social:

1) a crença da sociedade no mercado livre; 2) a visão do indivíduo como autoempreendedor; 3) o culto da excelência como forma de aperfeiçoamento individual e coletivo; 4) o culto de símbolos $e$ figuras emblemáticas, como "palavras de efeito" (inovação, sucesso, excelência) e "gerentes heróis"; e 5) a crença em tecnologias gerenciais que permitem racionalizar as atividades organizadas grupais.

Historicamente, o management caracterizou-se pela interdisciplinaridade, capaz de abarcar um amplo leque de conhecimentos e, simultaneamente, dar margem a análises superficiais e a confusões teóricas e conceituais (FERNANDES, 2002). Ao mesmo tempo, o campo nunca se configurou como uma área de conhecimento bem demarcada e restrita à instância teórica, dando ensejo a que praticantes desprezassem o conhecimento visto como originado na academia e para que fosse concedido à administração - em sua faceta pop - o status de setor de negócios. Assim, o pop-management surge como uma indústria emergente e bem-sucedida, assentada em quatro pilares inter-relacionados e que se reforçam mutuamente: (a) as escolas de administração, (b) as empresas de consultoria, (c) os gurus empresariais e (d) a mídia de negócios (MICKLETHWAIT; WOOLDRIDGE, 1998).

\section{Literatura "pop" em administração}

O quarto pilar do pop-management - a mídia de negócios - refere-se ao conjunto que abrange livros, revistas e jornais de negócios e de gestão empresarial; todos artefatos da cultura do gerencialismo. Um dos veículos de maior destaque são os livros de pop-management, que vêm experimentando tiragens crescentes nos últimos anos (WOOD Jr.; DE PAULA, 2003, p.7):

Definimos livro popular de gestão como um texto produzido por um agente do campo do management - consultor, guru, jornalista, professor ou executivo - com a finalidade de difundir suas ideias em grande escala e legitimar seu papel de produtor ou disseminador do conhecimento em gestão empresarial. Tais "produtos" fazem parte da literatura de pop-management, publicações da área de negócios produzidas, comercializadas e consumidas em ciclos curtos, com forte orientação para o mercado.

Os livros pop apresentam discurso unificado, linguagem simplificada e narrativa pasteurizada. Através da padronização de conceitos, modelos e métodos, os autores abordam problemas complexos por meio de construções simbólicas, criando a impressão de que se pode facilitar a compreensão da questão e a tomada de decisão decorrente de seu tratamento. Os textos são geralmente escritos por consultores que dão conselhos sobre como se chegar aos parâmetros de sucesso valorizados pelo 
sistema produtor, sempre advogando o uso de novas ferramentas de gestão. Os livros e artigos são prescritivos e imperativos no tom, impondo noções de "certo e errado", "moderno e antiquado" (NEPOMUCENO; MOREIRA, 2004). Rodrigues, Morin e Strehlau (2009, p.236) lembram que a mídia gera transformações substantivas "na forma como as pessoas produzem sentidos sobre fenômenos sociais e se posicionam em relação a eles", assumindo "papel fundamental na construção e na seleção de repertório" no cotidiano das pessoas.

Os casos de sucesso (geralmente, histórias sobre grandes corporações norte-americanas) e as receitas prontas (os onipresentes "dez passos" para "vencer") são exemplos dessa linguagem midiática (WOOD Jr.; DE PAULA, 2006). Tais narrativas também guardam aspectos facilmente identificáveis de controle social: "as histórias de sucesso disseminadas pela mídia de negócios auxiliam na redução das tensões geradas pela instabilidade do mundo do trabalho contemporâneo" (WOOD Jr.; DE PAULA, 2003, p.9).

Acrescente-se a esse quadro a contaminação das referências em administração pelos modismos da gestão; modelos administrativos gerados de forma espetaculosa, utilizados acriticamente e descartados como panaceias gerenciais, num curto ciclo de vida (MENDES, 2004). Uma das razões mais fortes para a adoção de modismos seria decorrente dos problemas na formação do administrador, uma vez que a baixa qualidade do seu processo de aprendizagem pode fazer com que manifeste um discernimento superficial da realidade que se lhe apresenta (WOOD Jr., 2001).

As novas abordagens administrativas, vendidas como soluções para todos os males, resultam na proliferação de receitas e pacotes gerenciais que alimentam o mercado da literatura $p o p$ em gestão, recrudescendo a tendência de adoção de novos modismos (MENDES, 2004). Os livros de pop-management ajudam a difundir as modas e modismos gerenciais, uma vez que alimentam o crescimento das informações sobre negócios e consolidam sua aceitação na sociedade (WOOD Jr.; DE PAULA, 2003), a despeito do reducionismo e dos condicionantes ideológicos neles embutidos (NEPOMUCENO; MOREIRA, 2004).

Retornando aos estudantes de administração, não é difícil compreender que esse tipo de abordagem despreocupada pode criar ideias equivocadas para quem não teve acesso a outras fontes de informação (FERNANDES, 2002). Como a linguagem utilizada é simples, nem todos os leitores conseguem de forma crítica absorver o conteúdo apresentado. Assim, muitos são persuadidos a crer que podem, com um esforço bem direcionado, atingir o mesmo patamar do executivo estrangeiro que conta sua milagrosa história de sucesso.

\section{Os autores "pop" vão à escola}

Como se sabe, o projeto de globalização provocou uma pasteurização de culturas diversas em um amálgama comandado pela economia neoliberal, com a consequente proliferação de excluídos em todas as instâncias (MENDES, 2004). Com a perda da capacidade de previsão, decisões são tomadas sem levar em conta o futuro distante (Ibidem). No mundo gerencial, essa questão se traduz no problema de uma "obsessão pelas novidades, que parece caracterizar muitos executivos, levando à adoção e à utilização sem critério" (WOOD Jr.; DE PAULA, 2003, p.109).

Nesse reino do efêmero e do descartável (LIPOVETSKY, 2004), se a influência dos livros de gestão é notada nas agendas dos executivos, mais notável é sua disseminação entre professores, estudantes e pesquisadores (WOOD Jr.; DE PAULA, 2003, 2006). Essa utilização universalizada alavanca o consumo da literatura de popmanagement, fazendo assim com que ela se alimente de si mesma. Os consumidores ficam no limite entre, de um lado, o conhecimento científico e, do outro, o senso comum que utiliza indução sobre a experiência (MATTOS, 2000, p.3): prevalece, então, a crença de que, "caso após caso, se funcionou para outros, funcionará para você". Entretanto, escritores e editores não contam com uma base teórica sólida o suficiente para a arquitetura de livros que discorram minimamente sobre ideias e práticas gerenciais (WOOD Jr.; DE PAULA, 
2002b). Fernandes (2002, p.34) acrescenta que "os livros são escritos para as massas, de uma forma superficial, enfeitados com frases vazias de significado".

O ciclo parece simples de compreender. Os livros populares de gestão são escritos por autores com formação duvidosa (alguns assumem e professam o próprio charlatanismo) ou desvinculada do tema apresentado. Outra possibilidade é a "adaptação" (plágio, compilação, tradução com um toque pessoal) de autores estrangeiros (preferencialmente, norte-americanos). Porém, da mesma maneira, aqueles que "adaptam" não têm formação adequada para realizar um trabalho coerente; seus livros são consumidos por estudantes, professores e pesquisadores que passam tal conhecimento adiante, muitas vezes, por meio de resumos publicados na internet ou por jogos de transparências distribuídos em palestras. Muitos livros são usados em cursos especializados, universidades e em programas de MBA.

A consequência disso é que formam-se alunos com níveis de conhecimento quantitativa e qualitativamente questionáveis que, posteriormente, ingressam no mercado de trabalho e passam a aplicar o conhecimento adquirido daquela forma. Para esses jovens, uma consequência extremamente negativa é vir a tomar decisões gerenciais traduzidas em práticas mal empregadas, que geram a necessidade de funcionários capazes de decifrar e resolver os problemas naturalmente decorrentes desse processo desastroso. Mais uma vez, todos recorrem a mais estudos e maior especialização. Retornam, então, às mesmas instituições de ensino, e o ciclo vicioso reinicia, fomentando de modo ainda mais vigoroso a indústria do management. Em escolas preocupadas mais com o número de inscritos do que em produzir conhecimentos que atendam às demandas sociais - cujos professores, compelidos pelo ímpeto da expansão da área, atendem aos desígnios de alunos que pressionam por formas imediatistas de saber (MATTOS, 2000) -, o risco está em aumentar ainda mais o grau de ignorância.

Nos processos seletivos para os melhores cargos, são aprovados não os candidatos que possuem melhor bagagem teórica e/ou técnica, mas aqueles que sabem usar o gerúndio à maneira dos operadores de telemarketing e aqueles que repetem as lições aprendidas nos livros pop, carregando as tintas nas frases de efeito (CARVALHO; GRISCI, 2002). Assim, os estudantes das melhores escolas se ressentem de não possuir tarimba para abocanhar as melhores vagas e retornam às suas escolas solicitando aos mestres a leitura óbvia que garantirá a aprovação nas entrevistas feitas por profissionais de recursos humanos, que, por sua vez, conhecem essencialmente os livretos pop. Uma vez aprovados para o emprego, a discussão na hora do almoço irá girar em torno dos últimos best-sellers em gestão, fazendo com que os estagiários e trainees não-iniciados sintam-se excluídos do restante da "tribo". Nos seminários de final de ano, são festejados os gurus que escrevem os livros pop. Esse debate estende-se inevitavelmente para a sala de aula. A partir do momento em que os professores cedem a todas essas formas de pressão, a literatura pop passa definitivamente a ser utilizada como referência acadêmica por professores e estudantes de administração e, mesmo, de outras áreas (WOOD Jr.; DE PAULA, 2006).

\section{O “pop-management" das bruxas e dos budas}

A produção dos livros populares de gestão engloba diferentes estilos, caracterizando-se ultimamente uma tendência a misturar autoajuda e esoterismo com negócios (WOOD Jr.; DE PAULA, 2003), de tal forma que uma das principais funções dos livros de pop-management é curar a ansiedade e a insegurança diante do mundo competitivo e acelerado em que vivem os administradores. De fato, em recente pesquisa, Wood Jr e de Paula (2006) reconheceram a predominância de discursos apaziguadores, falsamente questionadores, carregados de simbolismo moral, fantasiosos e maniqueístas - característicos da literatura religiosa - em três das mais importantes revistas brasileiras sobre gestão.

De fato, o contato com a literatura de negócios estruturada sob o signo do esoterismo ou da autoajuda pode causar nos leitores uma sensação passageira de conforto e, até mesmo, transmitir uma falsa impressão de segurança diante dos desafios do mundo. Entretanto, esse efeito não se deve aos conhecimentos adquiridos por meio da leitura, mas pela linguagem de convencimento fundada em falsa sabedoria, amplamente usada em tais livros; precisamente, a mesma narrativa empregada nos livros de autoajuda e esotéricos. Alguns livros trazem um capítulo especial para a religião, geralmente, enfatizando princípios morais universais ou dogmas compartilhados pelas diversas crenças. Outros livros valem-se de anjos e magia para permitir que se atue num 
mundo em que se faz mapa astral de empresas com base na data de fundação, em que são fechados negócios com base em numerologia e em que se deixa de contratar funcionários em virtude de quiromancia.

As duas citações que aparecem na sequência - também presentes nos questionários elaborados para a etapa empírica desta pesquisa - foram obtidas em dois best-sellers do pop-management. Elas ilustram como os livros de negócios incorporaram a narrativa vazia, vaga, pretensiosa e fantasiosa recorrente nos textos de esoterismo e autoajuda. O primeiro trecho foi extraído de Quem mexeu no meu queijo? (SPENCER, 2002, p.56) e o segundo trecho está em O monge e o executivo (HUNTER, 2004, p.115).

- Começando a correr pelo corredor escuro, Haw sorriu. Ainda não se dera conta disso, mas estava descobrindo o que alimentava a sua alma. Estava se libertando e acreditando que havia algo de bom à sua frente, embora não soubesse exatamente o que era.

- Uma das coisas que eu logo descobri foi que as pessoas com problemas psicológicos sofrem muitas vezes do que eu chamaria de "doenças da responsabilidade". Os neuróticos assumem responsabilidades demais e acreditam que tudo o que acontece é por culpa deles.

À medida que os autores pop percebem que não existe, virtualmente, nenhuma resistência crítica ao despejo de suas ideias no mercado editorial - e que, ao contrário, quanto mais estapafúrdio é o livro, maiores são as chances de sucesso comercial -, abre-se espaço para toda sorte de bobagens. Caso não se estivesse diante de um quadro tão deprimente para o desenvolvimento do saber em administração, a situação chegaria a ser risível, a julgar pelos títulos dos livros. Dois exemplos fantásticos são Se você não tem bunda, use laços no cabelo... e outras lições (de negócios) que aprendi com minha mãe (CORCORAN; LITTEFIELD, 2004) e $O$ que podemos aprender com os gansos (RANGEL, 2003), que tem as versões I e II, ambas campeãs de vendas no mundo pop em gestão.

\section{Procedimentos metodológicos}

A metodologia que encaminhou a pesquisa está descrita nas quatro partes desta seção. Primeiro de tudo, descrevem-se o universo e a amostra; logo após, o processo de coleta dos dados. A seguir, discorre-se sobre os procedimentos para tratar e analisar os dados obtidos. Na última subseção apresentam-se algumas limitações do estudo.

\section{Universo e amostra}

O universo estipulado da pesquisa de campo comportou os possíveis consumidores da literatura de popmanagement - o público-alvo visado pelas editoras. Entre esses consumidores potenciais, estão incluídos não apenas estudantes de graduação e de pós-graduação em administração e em áreas afins, mas também qualquer profissional envolvido com atividades em organizações produtivas, bem como os aspirantes a atuar nesse mercado; todos submetidos ao discurso onipresente da "competitividade", da "agilidade" e da "empregabilidade", termos com que a literatura pop pretende se alinhar.

Decidiu-se restringir a pesquisa empírica à subpopulação composta pelos estudantes de administração no Rio de Janeiro, selecionando-se uma amostra de conveniência constituída por estudantes com matrícula ativa entre o quinto e o nono semestres letivos em uma universidade pública localizada nessa cidade e que já estivessem cumprindo estágio profissional. Dessa forma, esperava-se que a amostra contivesse apenas pessoas que já tivessem tido certo contato com a literatura acadêmica em administração e também com a literatura pop. A amostra efetiva, de natureza não probabilística, mas atendendo a critérios de acessibilidade e tipicidade (COOPER; SCHINDLER, 2003), ficou composta de 36 sujeitos, com idades variando entre 19 e 25 anos.

\section{Coleta de dados}

O instrumento escolhido para a coleta de dados foi um questionário (VERGARA, 2007), aplicado no pátio da universidade ou em salas de aula, conforme a oportunidade. O questionário era bastante simples, sendo 
composto de um pequeno espaço para identificação, de um guia para responder às perguntas, e apresentando em seguida as questões de múltipla escolha (com apenas três alternativas), que consistiam em trechos selecionados de livros previamente classificados pelos pesquisadores como de pop-management, de autoajuda e esotéricos.

Os trechos foram selecionados em 18 obras, incluindo seis livros de autoajuda - entre eles, os best-sellers Inteligência emocional (GOLEMAN, 1995) e Como fazer qualquer pessoa se apaixonar por você! (LOWNDER, 1999) -, seis livros sobre pop-management, incluindo os emblemáticos $O$ monge e o executivo (HUNTER, 2004) e Quem mexeu no meu queijo? (JOHNSON, 2002), e seis livros esotéricos, alguns deles creditados a importantes líderes religiosos, tais como o Dalai Lama (DALAI LAMA; CUTLER, 2003) e Allan Kardec (1999).

Em nenhum caso se identificava título ou autoria do livro. O único trabalho do respondente era marcar com um "X" o espaço que identificaria o trecho como pertencente a um dos três gêneros. Essa classificação, embora baseada na própria classificação editorial da obra (quando coube) ou na notoriedade do autor, não foi validada. Para dar uma ideia do escopo dos trechos, é mostrado no quadro 1 um fragmento exemplificativo. Como se pode observar, não foi utilizada a expressão "pop-management" ao apresentar a pergunta ao respondente, de modo a evitar induzi-lo em relação a uma eventual carga negativa (ou positiva) que a expressão pudesse conter.

No fragmento do questionário reproduzido no quadro 1, tem-se, de cima para baixo: Mishima (1987), um clássico da autoajuda; em seguida, Xavier (2003), uma das mais importantes obras esotéricas brasileiras; e Holanda (1996), típico livro pop. É interessante notar a semelhança entre o primeiro e o terceiro trechos, que recorrem à sabedoria oriental para marcar suas "lições de vida".

\section{Quadro 1 - Fragmento do questionário da pesquisa}

Acredito que na China era hábito, desde os tempos antigos, só realizar uma reunião depois de ter convencido todas as pessoas esperadas, de modo a haver consenso na reunião. Sempre que tiver de haver uma conferência, deve-se primeiro falar com cada pessoa interessada e, em seguida, reunir aqueles cuja opinião precisamos ouvir, e tomar uma decisão. Sem isso, haverá inevitavelmente pessoas que ficarão ressentidas com a decisão.

\section{( ) AUTOAJUDA ( ) LIVRO DE GESTÃO ( ) ESOTÉRICO}

Sem a cooperação, é impossível atender com eficiência. O camponês que cultiva a terra alcança a gratidão dos que saboreiam os frutos. O servidor que obedece, construindo, conquista os superiores, companheiros e interessados no serviço. E nenhum administrador intermediário poderá ser útil aos que ama, se não souber servir e obedecer nobremente.

\section{( ) AUTOAJUDA ( ) LIVRO DE GESTÃO ( ) ESOTÉRICO}

Os japoneses utilizam a boneca Daruma, que é um símbolo que ajuda a visualizar a obtenção de resultados. No lugar dos olhos da boneca estão duas áreas brancas. A primeira pupila é colocada quando se fixa uma meta e a segunda, quando a meta é atingida. Durante o processo, o olho ausente irá destacar constantemente que a meta ainda não foi alcançada, levando a um esforço maior.

\section{( ) AUTOAJUDA ( ) LIVRO DE GESTÃO （ ) ESOTÉRICO}

\section{Tratamento e análise dos dados}

As respostas dos 36 estudantes foram transcritas em uma matriz de dados composta de 36 linhas (os respondentes) e 18 colunas (os trechos), logo transformada em planilha Excel do mesmo tamanho e, a seguir, em planilha de dados do SPSS, versão 12.0. Aquela matriz inicial pode ser descrita por seu termo genérico: 


$$
\mathrm{a}_{\mathrm{ij}}=\text { classificação feita pelo indivíduo i acerca do trecho lido } \mathrm{j} \text {. }
$$

Foi usada a codificação $a_{i j}=1,2$ ou 3, conforme o trecho provenha de um livro de autoajuda (1), pop ou gestão (2) ou esotérico (3). As respostas ao questionário são, portanto, do tipo categórico (ou nominal), sendo a operação quantitativa básica a contagem de frequências.

Nesta pesquisa, o foco são os padrões de conjunto, em vez de serem consideradas respostas individuais ou textos específicos, embora o conhecimento de características específicas (por exemplo, as demográficas) pudesse ajudar em algumas interpretações. Assim, somaram-se as respostas correspondentes a cada um dos gêneros oferecidos como resposta, sendo essas respostas totais que recebem mais atenção neste estudo.

O objetivo da pesquisa foi (a) descobrir, através da percepção manifestada nas respostas do conjunto de leitores, se os respondentes foram capazes de diferenciar o tipo de leitura que estão consumindo, e, em caso contrário, (b) procurar conhecer a natureza do correspondente "erro de classificação".

Por conseguinte, a análise dos dados pretende indicar respostas a três perguntas:

a frequência de acertos e de erros na classificação do trecho pelo respondente mostra algum padrão?

essa frequência de acertos e de erros depende do tipo (gênero) de obra?

é possível estabelecer ex post alguma tipologia da percepção dos respondentes sobre os textos? Em caso afirmativo, como interpretar tal (ou tais) tipologia(s)?

Devido à natureza e ao tamanho da amostra, a análise dos dados não deve utilizar abordagens estatísticas que requeiram grandes amostras ou conhecimento prévio sobre as distribuições de probabilidade envolvidas. Assim, apelou-se a técnicas não-paramétricas para responder às duas primeiras, a saber, os testes de Quiquadrado (WONNACOTT; WONNACOTT, 1977, cap.17), de Wilcoxon (SIEGEL, 1981, cap.5) e de Friedman (ibidem, cap. 7).

As técnicas não-paramétricas são particularmente adequadas aos dados das ciências do comportamento. A aplicação dessas técnicas não exige hipóteses quanto à distribuição da população que originou a amostra. Em geral, tais hipóteses são restritivas e raramente se verificam para aqueles dados. Além disso, a estatística nãoparamétrica pode ser aplicada a dados que estejam medidos apenas como ordenações, ou mesmo, em certos casos, para estudo de variáveis nominais (SIEGEL, 1981, cap.1). Ainda de acordo com Siegel (1981, p.34), os testes não-paramétricos oferecem mesmo certas vantagens a eles específicas.

A tipologia empírica que vai constituir a resposta à terceira pergunta de pesquisa foi obtida por meio de uma técnica multivariada que, apesar de não-estatística, fornece respostas "ótimas" ao problema proposto, a saber, a análise de grupamentos (cluster analysis; cf. HAIR et al, 1998, cap.9).

\section{Limitações do método}

A metodologia escolhida para o estudo apresenta algumas limitações. Em primeiro lugar, é possível que o reduzido grupo selecionado para o questionário não tenha sido representativo do universo estudado; uma compensação a essa limitação poderia ser o grau de confiança estatística nos testes realizados. Além disso, a escolha de trechos específicos dos textos pode ter influência na resposta. Finalmente, muitos trechos foram retirados de livros conhecidos em seus gêneros, e alguns respondentes poderiam já ter tido contato prévio com aquele material. Cabe assinalar que a maioria dessas limitações engendra erros não-amostrais, que não podem ser corrigidos ampliando-se a amostra (BLALOCK, 1972).

\section{Resultados}

Nesta seção aparecem os resultados numéricos obtidos. Primeiro, são apresentados os resultados descritivos, seguidos dos testes e técnicas estatísticos. 


\section{Resultados descritivos}

A matriz básica para apresentar e testar os resultados aparece na tabela 1, mostrando a frequência absoluta dos totais de respostas por tipo de leitura e combinando classificações certas e erradas. Como a diagonal representa os acertos, pode-se constatar que o maior número de acertos ocorreu com os textos de autoajuda, cuja frequência foi cerca de $37 \%$ superior à soma da frequiência de acertos nos outros dois tipos.

Tabela 1 - Respostas certas e erradas por tipo de leitura: original e interpretado*

\begin{tabular}{llccc}
\hline & & \multicolumn{3}{c}{ Trecho original } \\
\hline \multirow{3}{*}{ Trecho interpretado } & Autoajuda & Pop & Esotérico \\
\cline { 2 - 5 } & Autoajuda & 81 & 94 & 94 \\
\cline { 2 - 5 } & Pop & 118 & 29 & 92 \\
\cline { 2 - 5 } & Esotérico & 17 & 93 & 30 \\
\hline
\end{tabular}

*Nota - os totais das colunas são todos iguais a 216.

Fonte: ados da pesquisa

Na tabela 2 se vê o resultado da transformação da tabela 1 em percentagens tomadas por coluna. Vale notar que a escolha entre linhas e colunas nas duas tabelas não é arbitrária, devendo aparecer a variável independente nas colunas e a variável dependente nas linhas (SILVEY, 1975, p. 53). Consequentemente, os percentuais devem, em princípio, ser tomados com relação aos totais das colunas. Esse alerta será útil na próxima seção, quando se testa a existência de relações significativas entre aspectos relativos às respostas obtidas.

Tabela 2 - Respostas percentuais para cada tipo de leitura: original e interpretado

\begin{tabular}{llccc}
\hline & \multicolumn{3}{c}{ Trecho original } \\
\hline & & Autoajuda & Pop & Esotérico \\
\hline \multirow{3}{*}{$\begin{array}{l}\text { Trecho } \\
\text { interpretado }\end{array}$} & Autoajuda & $37,5 \%$ & $43,5 \%$ & $43,5 \%$ \\
\cline { 2 - 5 } & Pop & $54,6 \%$ & $13,4 \%$ & $42,6 \%$ \\
\cline { 2 - 5 } & Esotérico & $7,9 \%$ & $43,1 \%$ & $13,9 \%$ \\
\hline
\end{tabular}

Fonte: dados da pesquisa.

Se houvesse acerto completo, então a matriz contida na tabela 2 seria uma matriz diagonal, com 100 na diagonal principal e zero em todas as outras posições. Poder-se-ia argumentar que, quanto mais a distribuição efetiva das respostas se "afastar" daquela matriz diagonal, mais "indesejável" será a situação, no sentido da ocorrência de erros de classificação pelos respondentes. Não é necessário qualquer teste para constatar que os acertos foram mais frequentes para os livros de autoajuda e que os percentuais de erro nos dois outros tipos são bem altos, em torno de $86 \%$.

No caso das respostas (certas ou erradas) dadas para cada gênero de literatura em relação ao total (648), mostradas na tabela 3, os respondentes marcaram: 269 como de autoajuda, o que equivale a 41,51\% do total; 239 como de livros de gestão, o que corresponde a 36,88\% do total; e 140 respostas como de livros esotéricos, o que corresponde a $21,60 \%$ do total de respostas. Em termos estritamente numéricos, parece que se pode dizer que o gênero autoajuda atrai um pouco mais do que os outros dois, sendo os esotéricos os trechos menos "atraentes". No entanto, seria necessário um teste estatístico para decidir se a diferença entre autoajuda e pop é significativa. 
Tabela 3 - Atração percebida de cada tipo de leitura

\begin{tabular}{ccc}
\hline Tipo de leitura & $\begin{array}{c}\text { Número de } \\
\text { respostas }\end{array}$ & Atração relativa \\
\hline Autoajuda & 269 & $41,5 \%$ \\
\hline Pop-management & 239 & $36,9 \%$ \\
\hline Esotérica & 140 & $21,6 \%$ \\
\hline Total & 648 & 100 \\
\hline
\end{tabular}

Fonte: - dados da pesquisa

\section{Análise multivariada}

A primeira questão - "a frequência de acertos e erros na classificação do trecho pelo respondente mostra algum padrão?" - pode ser respondida por meio de um teste para determinar se existe diferença significativa entre os gêneros quanto aos acertos e erros de classificação. Enfatizando o caso mais interessante dos acertos, a aplicação do teste de Friedman resulta na rejeição da hipótese de que não haja diferença nos acertos entre os três tipos, com $\mathrm{p}<0,1 \%$. Olhando os números, pode-se argumentar que fica estabelecido o padrão de que o percentual de acertos para os trechos de autoajuda é significativamente maior do que o dos outros dois. Reforçando essa interpretação, o teste bilateral de Wilcoxon confirma que o gênero autoajuda é diferente de cada um dos outros dois (ambos, com $\mathrm{p}<0,1 \%)$, enquanto o resultado destes deve ser aceito como similar $(\mathrm{p}=$ $0,833)$.

A segunda questão - "a frequência de acertos e de erros depende do tipo (gênero) de obra?" - pode ser respondida pelo teste do Qui-quadrado para 4 graus de liberdade, já que a tabela de contingência gerada a partir da tabela 1 é 3x3. A aplicação resultou em um Qui-quadrado calculado igual a 124,684, muito superior ao valor tabelado de 18,5, correspondente a $\mathrm{p}=0,1 \%$. Assim, pode-se dizer que o padrão de erros e acertos depende significativamente do tipo de trecho apresentado ao leitor para classificação. Em outras palavras, o padrão observado de acertos e erros na classificação proposta não é acidental, mas depende, de modo estatisticamente significativo, da natureza do texto apresentado, sendo os de autoajuda os mais frequentemente classificados de forma correta.

A terceira questão - "é possível estabelecer ex post alguma tipologia da percepção dos respondentes sobre os textos? Em caso afirmativo, como interpretar tal (ou tais) tipologia(s)?" - foi respondida pela aplicação de uma técnica de agrupamento (clustering) hierárquico aos trechos selecionados. Foi utilizado apenas o default do procedimento, ou seja, a distância euclidiana aplicada aos elos médios entre grupos. O dendrograma resultante (cf. HAIR et al, 1998, cap. 9) aparece na figura 1 e revela que o grupo dos trechos de autoajuda - de números 1 , $6,7,11,14$ e 18 - é o primeiro (e na verdade o único) a ser percebido como grupo, apesar da adesão posterior de alguns trechos de outro gênero: quatro esotéricos - 2, 3, 13 e 17 - e um pop - 12. Essa fusão entre esotéricos e autoajuda é compreensível, pois um dos propósitos almejados pelo movimento esotérico é ajudar o desenvolvimento e a felicidade humanos. Os demais trechos se juntam sucessiva e independentemente àquele grupo, sugerindo que são percebidos isolada e separadamente pelos respondentes.

\section{Considerações finais}

Como alerta Caldas (2006, p.128), "a apreensão da informação para sua transformação em conhecimento crítico e transformador passa, necessariamente, pela leitura do mundo, sem o que a leitura da palavra não levará a nada". Seguindo as recomendações apresentadas por Wood Jr e de Paula (2006), este estudo procurou investigar como estudantes de administração consomem os livros identificados com o gênero de literatura que sustenta o sistema pop-management.

Os resultados sugerem que - provavelmente, em função das características de um sistema produtor que incorpora formas artísticas e subjuga possibilidades de conhecimento por meio da indústria cultural 
(ADORNO; HORKHEIMER, 1997) - parece estar em curso séria ameaça para o ensino da administração no Brasil. Deve-se acrescentar, todavia, que a própria percepção do sentido do trabalho em organizações produtivas pode contribuir negativamente para que os estudantes realizem suas leituras de forma deficiente durante o tempo da faculdade. De acordo com Haroche (2005, p.357), "o espírito de empresa, impulsionado atualmente por [...] uma atividade desenfreada submetida à urgência, desprovida de reflexão", não se harmoniza com a ideia de que pode levar anos para que um universitário leia e se aproprie do conhecimento necessário ao exercício de uma profissão.

\section{Figura 1 - Dendrograma de agrupamento dos trechos}

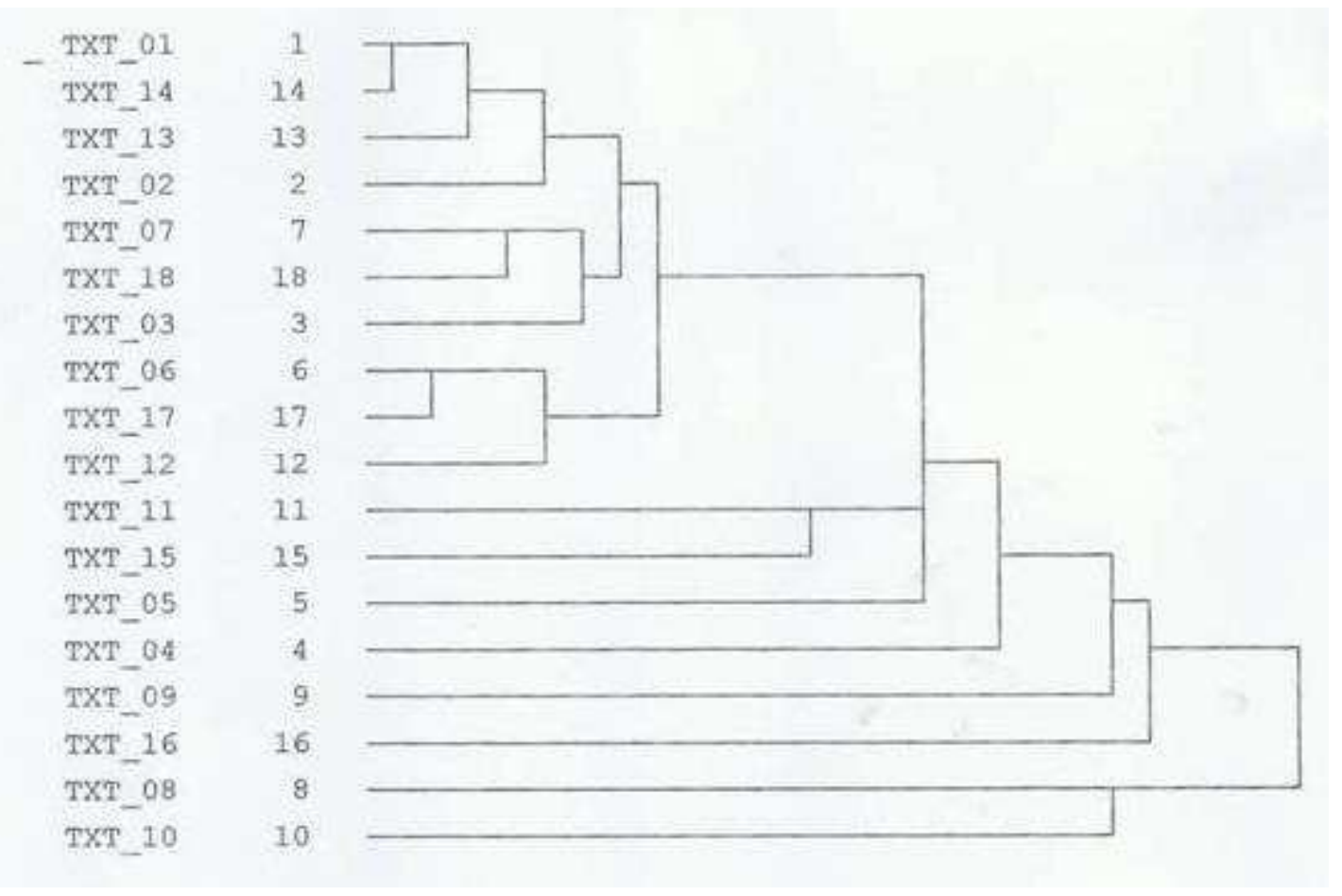

Fonte: dados da pesquisa

Não se pode ignorar, tampouco, as consequências deletérias para o ensino universitário da posição do empresariado brasileiro acerca da educação profissional para o trabalho em organizações, a qual vem privilegiando uma perspectiva funcionalista e acrítica do processo formativo, com ênfase na qualificação técnica e na aquisição de habilidades meramente operacionais (OLIVEIRA, 2003). Os autores deste estudo endossam a perspectiva de que, a despeito de serem infelizmente tachadas de "torres de marfim" por segmentos da sociedade menos afeitos aos bancos escolares, "as universidades têm enorme potencial de contribuir para a realização de transformações sociais” (GOULART; VIEIRA, 2008, p.94).

Como se viu, a pesquisa focalizou uma visão da demanda por leitura a partir de um questionário entregue a um grupo de estudantes de uma universidade pública que é parte da elite universitária do país. O objetivo foi analisar se esses jovens seriam capazes de identificar livros de "gestão" quando confrontados com trechos de livros diversos. Mais especificamente, o objetivo foi investigar se, do ponto de vista dos leitores, haveria diferenças perceptuais significativas entre a literatura pop-management, os livros de autoajuda e os livros esotéricos. Os resultados obtidos mostram que esses universitários "de elite" foram relativamente incapazes de distinguir os gêneros literários.

Considerando que há evidências mercadológicas de que o fenômeno pop-management parece ter definitivamente encontrado acesso rápido aos bancos escolares (MICKLETHWAIT; WOOLDRIDGE, 1998), é 
particularmente preocupante a confusão decorrente desse amálgama de gêneros, que tem início, talvez, até antes da graduação. Uma vez que a venda de livros pop está apoiada em forte esquema promocional, pode ser que a formação dos futuros administradores brasileiros esteja gravemente ameaçada.

Em função das claras características da literatura de pop-management - fácil assimilação, utilizada por profissionais supostamente bem-sucedidos e consultores de negócios, com utilização de recursos narrativos e discursos que se aproximam da realidade do leitor - os respondentes da pesquisa não foram capazes de diferenciar esse tipo de leitura dos livros esotéricos ou de autoajuda. Uma das possíveis razões para esse resultado é que os três tipos de literatura, de fato, têm as mesmas características em seus textos. Isso pode ser comprovado não só pelo fato dos respondentes não terem identificado os trechos de pop-management, mas também pela confusão de respostas referentes a cada trecho.

Portanto, pode-se cogitar que, do ponto de vista dos leitores, não existam diferenças perceptuais significativas entre a literatura pop-management, os livros de autoajuda e os livros esotéricos. A partir dessa constatação, sugere-se que aos livros de pop-management não deva ser creditada importância maior do que aquela dada aos livros de autoajuda ou esotéricos. Aos docentes, recomenda-se que sejam ainda mais cuidadosos ao selecionar as referências bibliográficas indicadas a seus discentes, pois uma formação acadêmica cada vez mais dependente do mundo pop pode significar, no longo prazo, o apodrecimento do conhecimento em administração, sem falar nas consequências óbvias para todos os participantes de instituições de ensino, para as organizações produtivas e para a sociedade. 


\section{Referências}

ADORNO, T.; HORKHEIMER, M. Dialética do esclarecimento: fragmentos filosóficos. Rio de Janeiro: Jorge Zahar, 1997.

BLALOCK, H. Social statistics. New York : McGraw-Hill, 1972.

CALDAS, G. Mídia, escola e leitura crítica do mundo. Educação \& Sociedade, v.27, n.94, p.117-130. jan./abr. 2006.

CARVALHO, M.; GRISCI, C. Gerenciamento de impressão em entrevista de seleção: camaleões em cena. In: ENCONTRO DA ASSOCIAÇÃO NACIONAL DOS PROGRAMAS DE PÓS-GRADUAÇÃO EM ADMINISTRAÇÃO, 26., 2002, Salvador. Anais... Salvador: Anpad, 2002.

COOPER, D. R.; SCHINDLER, P. S. Métodos de pesquisa em administração. 7.ed. Porto Alegre: Bookman, 2003.

CORCORAN, B.; LITTEFIELD, B. Se você não tem bunda, use laços no cabelo... e outras lições (de negócios) que aprendi com minha mãe. São Paulo: Planeta do Brasil, 2004.

DALAI LAMA; CUTLER, H. A arte da felicidade: um manual para a vida. São Paulo: Martins Fontes, 2003.

DEBORD, G. A sociedade do espetáculo. Rio de Janeiro: Contraponto, 1998.

FARIA, A. Mercado de ideias. GV executivo, v.5, n.5, p.33-37, nov./dez. 2006.

FERNANDES, J. Pós-modernismo e gestão de empresas: uma (re)leitura de Tom Peters. Percursos \& Ideias, n.5, p.3446, maio 2002.

FUGERE, B.; HARDAWAY, C.; WARSHAWSKY, J. Por que as pessoas de negócios falam como idiotas: um guia de combate à embromação. São Paulo: Best Seller, 2007.

GOLEMAN, D. Inteligência emocional. 33.ed. Rio de Janeiro: Objetiva, 1995.

GOULART, S.; VIEIRA, M. Desenvolvimento e organizações: as universidades como eixo de articulação entre o local e o global. Organizações \& Sociedade, v.15, n.45, p.91-106, abr.jun. 2008.

HAIR, J. et al. Multivariate data analysis. 5.ed. Upper Saddle River: Prentice Hall, 1998.

HAROCHE, C. Crise da consciência contemporânea e expansão do saber não cumulativo. Educação e Pesquisa, v.31, n.3, p.347-362, set./dez. 2005.

HOLANDA, F. Liderança para competitividade. Rio de Janeiro: Qualitymark, 1996.

HUNTER, J. O monge e o executivo: uma história sobre a existência da liderança. Rio de Janeiro: Sextante, 2004.

JOHNSON, S. Quem mexeu no meu queijo? Rio de Janeiro: Record, 2002.

KARDEC, A. O livro dos espíritos. São Paulo: Petit, 1999.

LIPOVETSKY, G. Os tempos hipermodernos. São Paulo: Barcarolla, 2004.

LOWNDER, L. Como fazer qualquer pessoa se apaixonar por você! Rio de Janeiro: Record, 1999.

MATTOS, P. O que diria Popper ao mercado de teoria administrativa? Uma "viagem" da epistemologia à aprendizagem. In: ENCONTRO DA ASSOCIAÇÃO NACIONAL DOS PROGRAMAS DE PÓS-GRADUAÇÃO EM ADMINISTRAÇÃO, 24., 2000, Florianópolis. Anais... Florianópolis: Anpad, 2000.

MELLO Jr., E.; MELLO, A. A educação de administradores em cursos noturnos: o quanto a literatura nos ensina sobre o cotidiano das salas de aula. In: ENCONTRO DA ASSOCIAÇÃO NACIONAL DOS PROGRAMAS DE PÓS-GRADUAÇÃO EM ADMINISTRAÇÃO, 32., 2008, Rio de Janeiro. Anais... Rio de Janeiro: Anpad, 2008.

MENDES, D. O caleidoscópio: modismo e pós-modernidade. In: ENCONTRO DA ASSOCIAÇÃO NACIONAL DOS PROGRAMAS DE PÓS-GRADUAÇÃO EM ADMINISTRAÇÃO, 28., 2004, Curitiba. Anais... Curitiba: Anpad, 2004.

MICKLETHWAIT, J.; WOOLDRIDGE A. Os bruxos da administração: como entender a babel dos gurus empresariais. Rio de Janeiro: Campus, 1998.

MINTZBERG, H. MBA? Não, obrigado! Uma visão crítica sobre a gestão e o desenvolvimento de gerentes. Porto Alegre: Bookman, 2006.

MISHIMA, Y. O Hagakure: a ética dos samurais e o Japão moderno. Rio de Janeiro: Rocco, 1987. 
NEPOMUCENO, L.; MOREIRA, L. Porque se diz o que se diz sobre aprendizagem e conhecimento organizacionais na literatura pop-management: uma crítica sobre os textos online da Associação Brasileira de Recursos Humanos e da Associação Brasileira de Treinamento e Desenvolvimento. In: ENCONTRO DE ESTUDOS ORGANIZACIONAIS, 3., 2004, Atibaia. Anais... Atibaia: Anpad, 2004.

OLIVEIRA, R. Empresariado industrial e a educação profissional brasileira. Educação e Pesquisa, v.29, n.2, p.249-263, jul./dez. 2003.

PARDINI, D.; FALCÃO, B.; SANTOS, R. Diversidade no meio universitário: influência dos atributos comportamentais e demográficos no relacionamento e desempenho de alunos de graduação em administração. In: ENCONTRO DA ASSOCIAÇÃO NACIONAL DOS PROGRAMAS DE PÓS-GRADUAÇÃO EM ADMINISTRAÇÃO, 32., 2008 , Rio de Janeiro. Anais... Rio de Janeiro: Anpad, 2008.

RANGEL, A. O que podemos aprender com os gansos. São Paulo: Panda Books, 2003.

RODRIGUES, A.; MORIN, E.; STREHLAU, S. A imagem de executivos na mídia: um estudo com jornais de Québec. Cadernos Ebape.BR, v.7, n.2, p.233-251, jun. 2009.

SAMPAIO, I.; SANTOS, A. Leitura e redação entre universitários: avaliação de um programa de intervenção. Psicologia em Estudo, v.7, n.1, p.31-38, jan./jun. 2002.

SIEGEL, S. Estatística não-paramétrica para as ciências do comportamento. São Paulo: McGraw-Hill, 1981.

SILVA, M.; FISCHER, T. Ensino de administração: um estudo da trajetória curricular de cursos de graduação. In: ENCONTRO DA ASSOCIAÇÃO NACIONAL DOS PROGRAMAS DE PÓS-GRADUAÇÃO EM ADMINISTRAÇÃO, 32., 2008, Rio de Janeiro. Anais... Rio de Janeiro: Anpad, 2008.

SILVEY, J. Deciphering data. London: Longman, 1975.

SPENCER, J. Quem mexeu no meu queijo. 34.ed. Rio de Janeiro: Record, 2002.

TAKAHASHI, A. Cursos superiores de tecnologia em gestão: reflexões e implicações da expansão de uma (nova) modalidade de ensino superior em administração no Brasil. In: ENCONTRO DA ASSOCIAÇÃO NACIONAL DOS PROGRAMAS DE PÓS-GRADUAÇÃO EM ADMINISTRAÇÃO, 32., 2008, Rio de Janeiro. Anais... Rio de Janeiro: Anpad, 2008.

VERGARA, S. Projetos e relatórios de pesquisa em administração. 8.ed. São Paulo: Atlas, 2007.

WONNACOTT, T.; WONNACOTT, R. Introductory statistics. 3.ed. New York: Wiley, 1977.

WOOD Jr., T. Organizações espetaculares. Rio de Janeiro: Editora FGV, 2001.

; DE PAULA, A. Pop-management. In: ENCONTRO DA ASSOCIAÇÃO NACIONAL DOS PROGRAMAS DE PÓSGRADUAÇÃO EM ADMINISTRAÇÃO, 25., 2001 Campinas. Anais... Campinas: Anpad, 2001.

maio/ago. $\overline{2002 a}$.

Pop-management: contos de paixão, lucro e poder. Organizações \& Sociedade, v.9, n.29, p.39-51,

Pop-management: pesquisa sobre as revistas populares de gestão no Brasil. In: ENCONTRO DA ASSOCIAÇÃO NACIONAL DOS PROGRAMAS DE PÓS-GRADUAÇÃO EM ADMINISTRAÇÃO, 26., 2002, Salvador. Anais... Salvador: Anpad, 2002b.

Viagem epistemológica às livrarias dos aeroportos. Iberoamerican Academy of Management Proceedings. In: 3rd INTERNATIONAL CONFERENCE, São Paulo, 2003.

; DE PAULA, A. A mídia especializada e a cultura do management. O\&S Organizações \& Sociedade, v.13, n.38, p.73-89, jul./set. 2006.

XAVIER, F. Nosso lar: a vida no mundo dos espíritos. 54. ed. Rio de Janeiro: Federação Espírita Brasileira, 2003. 